\title{
Histological evidence that diploid hybrids of Cobitis taenia and $C$. elongatoides (Teleostei, Cobitidae) develop into fertile females and sterile males
}

\author{
Dorota Juchno - Alicja Boroń
}

Received: 10 July 2017 / Revised: 26 January 2018/ Accepted: 29 January 2018/Published online: 9 February 2018

(C) The Author(s) 2018. This article is an open access publication

\begin{abstract}
In Europe, two bisexual fish species, Cobitis taenia (TT) and Cobitis elongatoides (EE), hybridized, producing diploid and polyploid clonal lineages. This study compared, for the first time, embryonic development, hatching success, sex ratio, body size and as well as reproductive ability based on the gonad histology of F1 reciprocal diploid hybrids (TE, ET) of both species. Hybrid F1 progeny showed the same proper pattern of embryonic and larval development. Among TE and ET offspring, slightly more females and males, respectively, occurred, but sex parity among 18-month-old hybrids was observed. Two- and three-year-old F1 hybrid females were mature, possessing all stages of oogenesis in their ovaries. Females (TE) back-crossed with $C$. taenia males had properly developing progeny. In testes of two- and three-year-old F1 hybrids, only early stages of spermatogenesis and pyknotic cells indicating the degeneration process were observed, but they exhibited an external feature (lamina circularis) of maturation. The results were confirmed by the structure of gonads that two sexual species, $C$. taenia and $C$. elongatoides, hybridize, producing F1 progeny of
\end{abstract}

Handling editor: Diego Fontaneto

D. Juchno $(\bowtie) \cdot$ A. Boroń

Department of Zoology, University of Warmia and

Mazury in Olsztyn, Oczapowskiego 5, 10-957 Olsztyn,

Poland

e-mail: juchno@uwm.edu.pl sterile males and fertile females. Hybrid females may participate in subsequent steps of speciation via hybridization and polyploidy or, on the contrary, represent an element of new species isolation.

Keywords Loaches - Crossing experiment - Gonad histology $\cdot$ Hybridization $\cdot$ Polyploidy

\section{Introduction}

Hybridization is a potentially powerful mechanism of diversification among vertebrates and can lead to adaptation through the creation of novel genotypes and morphologies (Hayden et al., 2010). In comparison with other vertebrates, interspecies or intergeneric hybrids are more frequently observed in fish (Comai, 2005). This is due to environmental factors, mainly external fertilization and a weak ethological isolating mechanism (Stolzenberg et al., 2009). Fish of the family Cobitidae, especially the Cobitis taxa, are an interesting object to study hybridization and subsequent polyploidization processes (Saitoh et al., 2010; Choleva \& Janko, 2013; Choleva et al., 2014).

The loaches of Cobitis in Central Europe occur mainly in mixed diploid-polyploid populations, in which individuals of spined loach $C$. taenia Linnaeus, 1758 and/or Danubian spined loach C. elongatoides Bacescu \& Maier, 1969 co-exist with their diploid and 
polyploid hybrids (Boroń, 2003; Choleva \& Janko, 2013; Choleva et al., 2014). Both of these species are small-sized, bottom dwelling fish. Although they are classified in the IUCN Red List Categories of Least Concern (LC) (IUCN, 2017) as an endangered and protected species in some European countries, mainly due to a decrease in the number of favorable habitats as well as a domination of allotriploid Cobitis females in most populations. Thus, the populations of these species are relatively rare. Among 26 karyologically recognized Cobitis populations distributed in Poland, only five were composed of exclusively $C$. taenia and only one was composed of exclusively $C$. elongatoides individuals (Boroń et al., unpublished).

Hybrids of Cobitis are indistinguishable in their external morphology from the parental species (Janko et al., 2012). C. elongatoides was discovered in Poland as a result of comparative chromosome research (Boroń \& Kotusz, 1999). This species is slightly distinguished by a single black spot, either oval or round in shape and located in the upper part of the caudal peduncle. C. elongatoides attained larger total length $(9.3 \mathrm{~cm}$ for males and $11.5 \mathrm{~cm}$ for females) than $C$. taenia (total length is $8.3 \mathrm{~cm}$ for males and $10.5 \mathrm{~cm}$ for females) (Boroń et al., 2006; Kotusz, 2008). C. taenia achieves sexual maturity in the first or the second (males) and second (females) year of their life (Juchno \& Boroń, 2006; Juchno et al., 2007). Otherwise, the maturity age of $C$. elongatoides is unknown. Matured Cobitis males exhibit sex dimorphic feature by the presence of a lamina circularis, a bony plate at the base of the pectoral fin ray (Juchno \& Boron, 2006; Juchno et al., 2007). Most of the Cobitis taxa existing in mixed populations are triploid hybrids, resulting in two-step hybridization of $C$. taenia $(2 n=48)$ with related species such as $C$. elongatoides ( $2 n=50)$ (Vasil'ev et al., 1989; Boroń, 2003; Juchno et al., 2007; Janko et al., 2007, 2012). In the first step, the hybridization of both of these species leads to the formation of diploid hybrids $(2 n=49)$. Such hybrid females producing diploid eggs and after fertilization with parental males may produce triploid hybrids, mainly females (Choleva et al., 2012). These females most often are dominant up to $95 \%$ of all Cobitis in mixed populations, whereas diploid hybrids are very rare (Boroń, 2003; Janko et al., 2007).

Previously, Janko et al. (2012) studied the origin of the taenia-elongatoides hybrid complex in a natural Polish hybrid zone and, with a combination of mtDNA and microsatellite markers, tested the direction of original crosses, maternal and paternal role and maintenance of diploid and polyploid clonal diversity. At the same time, Choleva et al. (2012) described the data of many crossing experiments to explain the role of hybridization and polyploidization during a process by which sexual reproduction reverses into clonality in spined loaches (Cobitis) to test the reproductive potential of reciprocal diploid hybrids of $C$. taenia and $C$. elongatoides. The current study also used a similar experiment design (but different in details) to understand and compare the early development of these reproductive pathways. Moreover, this study investigated the cause of hybrid-male infertility using gonad histology for the first time. Apart from the above-mentioned facts, the aim of the study was also to describe hatching success, the sex ratio and the average body length (SL) of diploid F1 hybrids (TE and ET) derived from reciprocal crossing between $C$. taenia (TT) and C. elongatoides (EE).

The presented investigations join the research stream of recent excellent findings about hybridization, hybrid fitness and asexuality (Choleva et al., 2012; Seehausen et al., 2014; Janko et al., 2017), contributing to the question of the potential role that hybrids play in the evolution of species.

\section{Materials and methods}

Experimental fish

Mature C. taenia (TT) and C. elongatoides (EE) were collected from an exclusively diploid population in Lake Legińskie $\left(52^{\circ} 51^{\prime} \mathrm{N}, 20^{\circ} 56^{\prime} \mathrm{E}\right)$ and in the Budkowiczanka River $\left(50^{\circ} 50^{\prime} \mathrm{N}, 17^{\circ} 39^{\prime} \mathrm{E}\right)$, respectively. Males were identified by the presence of a lamina circularis. The karyotype, as a species-specific feature of all parental individuals, was determined according to the methods described by Boron (2003).

\section{F1 formation}

Using five females (TT6, TT7, TT8, TT9, TT10) and one male (TT1) of C. taenia and one female (EE1) and two males (EE1, EE2) of C. elongatoides, six experimental crosses: TT6 $\times$ EE1, TT7 $\times$ EE1, TT8 $\times$ EE1, $\quad$ TT9 $\times$ EE2, $\quad$ TT10 $\times$ EE2 and EE1 $\times$ TT1 $($ Table 1) were performed. Artificial 
spawning was done in June, during the natural time for reproduction, but collected parental individuals were hormonally stimulated before crossing according to the routine fertilization method described in detail by Juchno et al. (2014). Similar to the method described by Juchno et al. (2016), the developing eggs were initially incubated in Petri dishes, and then in separate small aquaria with running water at $24^{\circ} \mathrm{C}$ under artificial light with a photoperiod similar to natural light conditions. A special electronic controller was used to maintain a stable temperature.

Embryonic and larval development of F1 hybrid progeny was observed and photographed using a stereomicroscope (Olympus) equipped with a digital camera. The developmental stages and the hatching success were defined as described for Danio rerio by Kimmel et al. (1995) and were compared with the developmental stages described for C. taenia and its polyploids (Juchno et al., 2016). The survival rates of larvae at 14 and 21 days post hatching (dph) were calculated and statistically analyzed using Pearson's Chi-squared test for each treatment.

Although the loaches at the age of seven months were juvenile, it was unknown if their sex could be recognized by the histology of gonads (Marconato \& Rasotto, 1989; Rasotto, 1992). Subsequently, some of the males at the age of 15 months had lamina circularis on their pectoral fin ray, but at 18 months of age all males had this bony plate. According to earlier results (Marconato \& Rasotto, 1989; Juchno \& Boroń, 2006), two-year-old Cobitis should be matured. Additionally, it was also decided to collect gonads from three-year-old specimens due to the fact that two-year-old males were infertile, to ensure that they did not attain maturity. Ovaries and testes of diploid F1 hybrid progeny at the ages of 7, 15 and 18 months and at 2 and 3 years were taken for histological analyses (Table 1). The gonads were fixed in Bouin's solution. Histological Section $(7 \mu \mathrm{m})$ were stained with hematoxylin and eosin. The developmental stages of oocytes were determined after Juchno et al. (2007), but the developmental stages of spermatogenesis were determined after Juchno \& Boron (2006). Five stages of maturity of the ovaries and testes have been distinguished (Tables 2, 3).

The body length of sexually mature F1 hybrids (111 TE, taenia-elongatoides, and 43 ET, elongatoidestaenia) at the age of 18 months (males possessing a lamina circularis) was measured. The standard length SL (in mm) of TE and ET hybrids of both sexes was compared by Student's $t$ test (in relation to a grouping variable; $P<0.05)$.

\section{F1 backcrossing}

In order to investigate the reproductive capacity of diploid F1 hybrids, subsequent crossing experiments were performed by the routine fertilization method
Table 1 Reciprocal crosses (female $\times$ male) between $C$. taenia (TT) and C. elongatoides (EE), age and number of F1 hybrid individuals used for histology of gonads

\begin{tabular}{llllc}
\hline Crossing & \multirow{2}{*}{ Age of F1 hybrids } & \multicolumn{3}{l}{ Number of F1 hybrid individuals } \\
\cline { 3 - 5 } & & F & M & Total \\
\hline TT6 $\times$ EE1 & 7 months & - & 5 & 5 \\
TT8 $\times$ EE1 & & 3 & 3 & 8 \\
EE1 $\times$ TT1 & & 6 & 6 & 12 \\
TT6 $\times$ EE1 & 15 months & 3 & 3 & 6 \\
EE1 $\times$ TT1 & & 1 & 5 & 6 \\
TT6 $\times$ EE1 & 18 months & 2 & 2 & 4 \\
EE1 $\times$ TT1 & & 5 & 3 & 8 \\
TT6 $\times$ EE1 & 2 years & 3 & 3 & 6 \\
TT7 $\times$ EE1 & & 2 & 4 & 6 \\
EE1 $\times$ TT1 & & 3 & 3 & 6 \\
TT6 $\times$ EE1 & 3 years & 2 & 0 & 2 \\
TT7 $\times$ EE1 & & 4 & 4 & 8 \\
EE1 $\times$ TT1 & & 2 & 2 & 4 \\
& Total & 36 & 43 & 79 \\
\hline
\end{tabular}


Table 2 The maturity stages in the ovary of C. taenia and C. elongatoides reciprocal hybrids according to histology

\begin{tabular}{lll}
\hline Oocyte stages (and oogonia) present in the ovary & Ovarian stage & Age of hybrids \\
\hline A, A1 & I Juvenile & was not observed \\
A, A1 and a single B & II Juvenile & 7- and 15- and 18-months \\
A, A1 and manly B & III Previtellogenic (Developing) & 15- and 18-months, \\
& & and 2 years \\
A, A1, B and single D & IV Cortical alveolus (Maturing) & 18-months, \\
A, A1, B, D and manly E & & 2 - and 3-years \\
\hline
\end{tabular}

Oogonia (A), early meiotic oocytes (A1), previtellogenic oocytes (B), cortical alveolus oocytes (D), oocytes accumulate yolk globules (E) and oocytes completely filled yolk globules (E)

Table 3 Maturity stages in the testes of C. taenia and C. elongatoides reciprocal hybrids according to histology

\begin{tabular}{lll}
\hline Spermatogonial stages present in the testes & Testes stage & Age of hybrids \\
\hline $\mathrm{Sg}$ & I Juvenile & Was not observed \\
$\mathrm{Sg}$ and Sc I & II Juvenile & 7- and 15-months \\
$\mathrm{Sg}, \mathrm{ScI}$ and Sc II & III Developing & 7- and 15- and 18-months; 2- and 3-years \\
$\mathrm{Sg}, \mathrm{ScI}, \mathrm{Sc}$ II and St & IV Maturing & Was not observed \\
$\mathrm{Sg}, \mathrm{ScI}, \mathrm{Sc}$ II, St and Sz & V Mature & Was not observed \\
\hline
\end{tabular}

Spermatogonia (Sg), Spermatocyte I (ScI), Spermatocyte II (Sc II), Spermatid (St) and Spermatozoa (Sz)

(Juchno et al., 2014). Two diploid F1 hybrid females (TE1, TE2) and four F1 (TE1, TE2 and ET1, ET2) three-year-old hybrid males were backcrossed with $C$. taenia (TT1) and C. elongatoides (EE1) males and with C. taenia (TT1, TT2, TT3, TT4) females, respectively according to following scheme: TE1 $\times$ TT1, TE2 $\times$ EE1; TT1 $\times$ TE1, TT2 $\times$ TE2, TT3 $\times$ ET1, TT4 $\times$ ET2 .

Fish sampling and valid animal use protocols for experiments were performed with the permission of the Polish Ministry of Environment (no. DLOPiK-op/ Ozgi-4201/V-5/5164/07/aj. and DOPOZGiZ.6401.10.12.2011.1s) and the Local Ethics Committee of Poland (no. 37/2007, 20/01 and 04/2011).

\section{Results}

Embryonic and larval development

An average of 329 eggs (from 169 to 575) and 713 eggs were obtained from $C$. taenia females and $C$. elongatoides female, respectively. The successive stages of embryonic and larval development of F1 hybrids resulting from reciprocal crosses between $C$. taenia and $C$. elongatoides were the same. The first meroblastic cleavage (Fig. 1a) occurred after $1 \mathrm{~h}$ and 25 min post fertilization and the next cleavages then occurred after c. 20-30 min (Table 4). The late blastula stage was observed after $9 \mathrm{hpf}$ (hours post fertilization). In this stage, the embryos shape changed from elongated to spherical (Fig. 1b). The embryos then began gastrulation through epiboly. The stage of $50 \%$ epiboly (the blastoderm covered half of the surface of the yolk sac) at $11 \mathrm{hpf}$ was observed and in $3 \mathrm{~h}$, at $14 \mathrm{hpf}$, gastrulation was finished $(100 \%$ epiboly, Fig. 1c) (Table 4). Somites were developed during the segmentation stage and the tail bud became more visible and the embryo was elongated. Primary organs differentiated from germ layers. The visual and auditory (with otoliths) organs were visible in the front part of the embryo, Kupffer's vesicle (Fig. 1d), and the first body movements occurred. At the end of this stage, the separation of the tail region was also observed (Table 4). Asynchrony was noted during embryonic development, especially at the segmentation and gastrulation stages (Fig. 1e). 

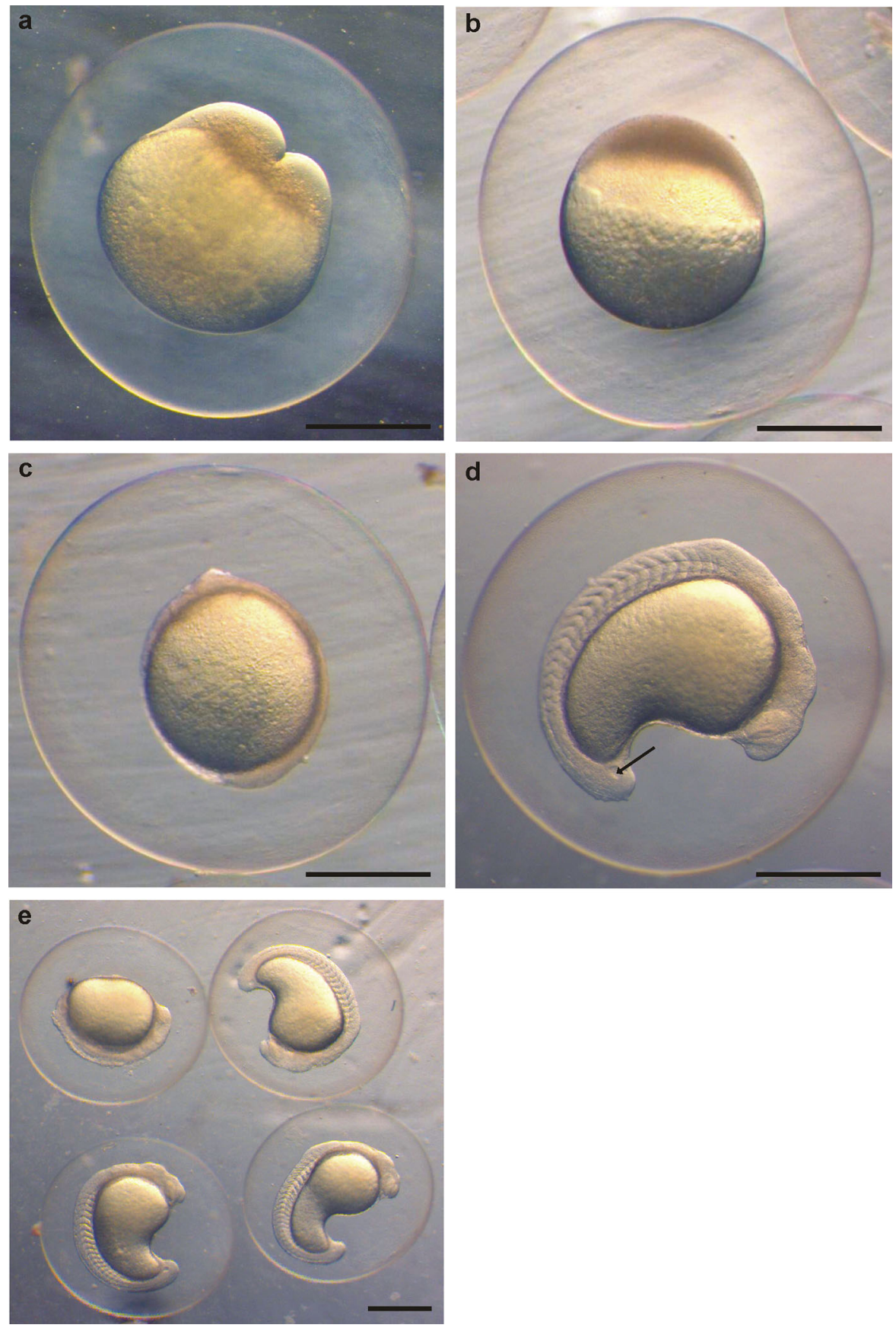

Fig. 1 Embryonic development of diploid F1 hybrids derived from reciprocal crossing between $C$. taenia and $C$. elongatoides. a Two blastomeres. b Blastula. c Blastopore closure, $100 \%$

Hatching occurred on the second/third day after fertilization (after $48 \mathrm{hpf}$, on average). Hatching success of ET was $15 \%$, whereas that of TE ranged from 17 to $59 \%$ ( $36 \%$ on average, $\mathrm{SD} \pm 4)$. The

epiboly. d 19 somites, arrow point to the Kupffer's vesicle. e Asynchrony during the segmentation stage. Bars $=500 \mu \mathrm{m}$

survival rate of larvae fluctuated from 75 to $89 \%$ (mean $82 \%, \mathrm{SD} \pm 12$ ) at $14 \mathrm{dph}$ and from 59 to $66 \%$ (mean $63 \%, \mathrm{SD} \pm 8$ ) at $21 \mathrm{dph}$. The survival rates were not statistically significantly different among 
Table 4 Developmental stages of diploid F1 hybrids derived from reciprocal crossing between C. taenia and C. elongatoides at $24^{\circ} \mathrm{C}$

\begin{tabular}{|c|c|c|}
\hline Stage name & $\begin{array}{l}\text { Time after } \\
\text { insemination }\end{array}$ & Notes \\
\hline $\begin{array}{l}\text { Cleavage period } \\
\text { 2-cell }\end{array}$ & $1 \mathrm{~h} 25 \mathrm{~min}$ & Figure 1a \\
\hline 4-cell & $1 \mathrm{~h} 40 \mathrm{~min}$ & Formation of blastomeres \\
\hline 8 -cell & $2 \mathrm{~h}$ & \\
\hline 32-cell & $2 \mathrm{~h} 40 \mathrm{~min}$ & \\
\hline 64-cell & $3 \mathrm{~h}$ & \\
\hline blastula & $9 \mathrm{~h}$ & Spherical shape (Fig. 1b) \\
\hline $\begin{array}{l}\text { Gastrulation } 50 \% \\
\text { epiboly }\end{array}$ & $11 \mathrm{~h}$ & Half coverage of the yolk by the blastoderm \\
\hline $100 \%$ epiboly & $14 \mathrm{~h}$ & Complete coverage of the yolk by the blastoderm (Fig. 1c) \\
\hline $\begin{array}{l}\text { Segmentation } 19 \\
\text { somites }\end{array}$ & $24 \mathrm{~h}$ & Formation of optic, auditory and Kupffer's vesicles (Fig. 1d) \\
\hline $\begin{array}{l}\text { The tail bud, } 25 \\
\text { somites }\end{array}$ & $28 \mathrm{~h}$ & $\begin{array}{l}\text { Separation of the tail region, constriction of the yolk, formation of the eye lens, visible } \\
\text { movement of embryo }\end{array}$ \\
\hline $\begin{array}{l}\text { Hatching (min. } \\
50 \%)\end{array}$ & $48 \mathrm{~h}$ & Figure $2 \mathrm{a}$ \\
\hline
\end{tabular}

analysed TE and ET progeny (Pearson's Chi-square test: $\left.\chi^{2}=0, \mathrm{df}=1\right)$.

The larvae were hatched from shell eggs by the tail (Fig. 2a). Larvae settled at the bottom of the aquarium and showed little ability to move. The body was covered with several melanophores. Clearly pigmented eyes, visible blood circulation and the gut were noted. The dorsal and ventral finfolds developed and the pectoral fin buds were shown. One day after hatching, four pairs of external filamentous gills and small pectoral fins were observed; numerous melanophores appeared over the entire body (Fig. 2b).

Surprisingly, a small number of larvae (c. $2 \%$ ) were characterized by deformities: mostly a shortened and C-shaped body, hypertrophy of the pericardium and lack of external gills (Fig. 2c).

\section{Gonad histology}

Since the histological structure of the gonads of reciprocal C. taenia and C. elongatoides F1 hybrids did not diverge, they are described below together.

All hybrid females had a single ovary. In 7-monthold females, the ovaries were in the II stage of maturity with mainly oocytes in the prophase (diplotene) of the first meiotic division (Fig. 3a, b). Early meiotic oocytes were larger than oogonia and they had a visible chromatin in the nucleus. Oogonia were characterized by a clearly defined, centrally placed nucleus. Single previtellogenic oocytes had a large nucleus, which occupied more than half of the cytoplasm (Fig. 3b).

The ovaries in 15-month-old hybrids were in the II or in the III stage of maturity. Many previtellogenic oocytes with cortical alveoli in the edge of cytoplasm were characterized in the III stage (Fig. 3c).

In 18-month-old hybrids, the ovaries were in the II, III and in the IV stages of maturity. In the ovaries classified as stage IV, besides previtellogenic oocytes, the cortical alveoli oocytes were easily distinguishable (Fig. 3d).

In 2- and 3-year-old hybrids, the ovaries were in the IV and V stages of maturity. In the ovaries at stage V, mainly vitellogenic oocytes (E) with yolk were observed (Fig. 3e, f). This is a typical structure of the ovaries for the pre-spawning period.

All hybrid males had paired testes. Both the testes of 7- and 15-month-old hybrids were in the II stage of maturity (Fig. 4a) with mainly spermatogonia and spermatocytes during the first meiotic division (spermatocytes I) or in the III stage of maturity where, apart from spermatogonia, spermatocytes I and II were also observed (Fig. 4b). 


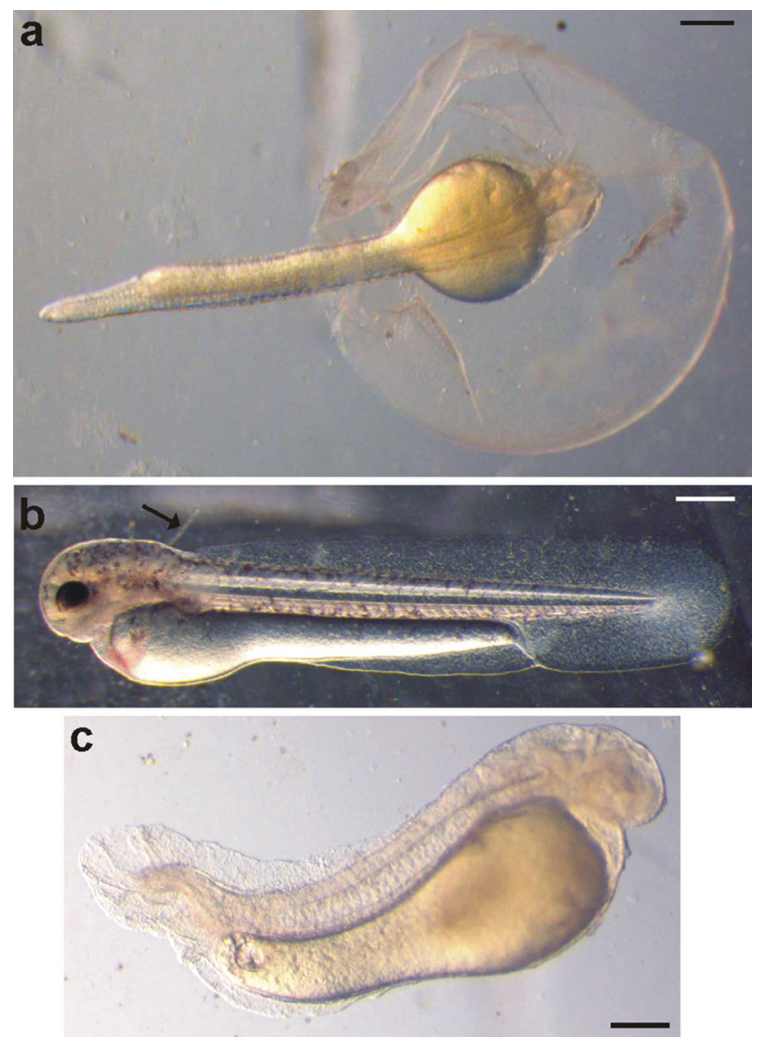

Fig. 2 Larval development of diploid F1 hybrids derived from reciprocal crossing between $C$. taenia and $C$. elongatoides. a Moment of hatching. b Larva $1 \mathrm{dph}$, arrow point to the external gills. c Deformities in larvae: a shortened and C-shaped body. Bars $=500 \mu \mathrm{m}$

All testes at 18 months, as well as in two-year-old and three-year-old hybrids, were in the III stage of maturity. However, in two-year-old and three-year-old hybrids, cells with degenerative symptoms, e.g. showing pyknosis, were observed (Fig. 4c, d). These cells were smaller in size than spermatogonia and spermatocytes I, and their nuclei showed a range of over-staining with hematoxylin in an irregular shape. Additionally, in three-year-old hybrids, more pyknotic cells were detected than in two-year-old males. In some testes, germ cells in the lumen of the tubules were also observed, but they were not spermatozoa (Fig. 4e, f). Although the cysts probably ruptured and stages prior to spermatozoa were released into the lumen of the tubules, no spermatid or spermatozoa were found in any testes.
Sex ratio and body size of hybrids

Taking into account taenia-elongatoides (TE) and elongatoides-taenia (ET) crosses separately, the sex ratio (females:males) among them was 1.3:1 and 0.75:1, respectively. However, if the sex ratio was calculated for all 18-month-old hybrids (TE and ET), it would be 1:1.

The average body length (SL) of the TE hybrids was $56.0 \pm 6.9 \mathrm{~mm}$. The SL of males ranged from 46.4 to $72.0 \mathrm{~mm}$ (mean $54.8 \pm 6.5$ ), while females ranged from 44.8 to $77.9 \mathrm{~mm}$ (mean $56.8 \pm 7.4$ ). However, the average SL of the ET hybrids was $59.7 \pm 6.0 \mathrm{~mm}$. The male SL fluctuated from 49.06 to $68.50 \pm \mathrm{mm}$ (mean 57.9 \pm 5.4 ), while in females it fluctuated from 49.7 to $73.03 \mathrm{~mm}$ (mean $62.1 \pm 6.4$ ).

The ET hybrids (all specimens, as well as females and males) were significantly $(P<0.05)$ longer than TE hybrids. The ET females were significantly $(P<0.05)$ longer than ET males, whereas the body length between females and males of TE hybrids did not differ significantly $(P>0.05)$.

\section{Reproductive capacity of F1 diploid hybrids}

As a result of the back-crossing between two-year-old TE females and $C$. taenia males, normally developing progeny were produced (Fig. 5a, b, c). In turn, backcrossing between the same TE female with a $C$. elongatoides male led only to dead gastrula embryos. In contrast, the back-crosses between $C$. taenia or $C$. elongatoides females with diploid, hybrid males (TE or ET) were impossible due to a lack of sperm.

\section{Discussion}

The results of this study have proven that in reciprocal F1 diploid C. taenia (TT) and C. elogatoides (EE) hybrids, embryonic and larval development, as well as further morphological development until maturity, occurred properly. The direction of crossing seems not to affect the obtained results. Two- and three-year-old F1 diploid hybrid (TE and ET) females achieved gonad maturity since all stages of oogenesis were observed in their ovaries. In turn, hybrid males did not achieve gonad maturity since their testes contained no spermatid or spermatozoa. Interestingly, the external features of sexual dimorphism, such as lamina 

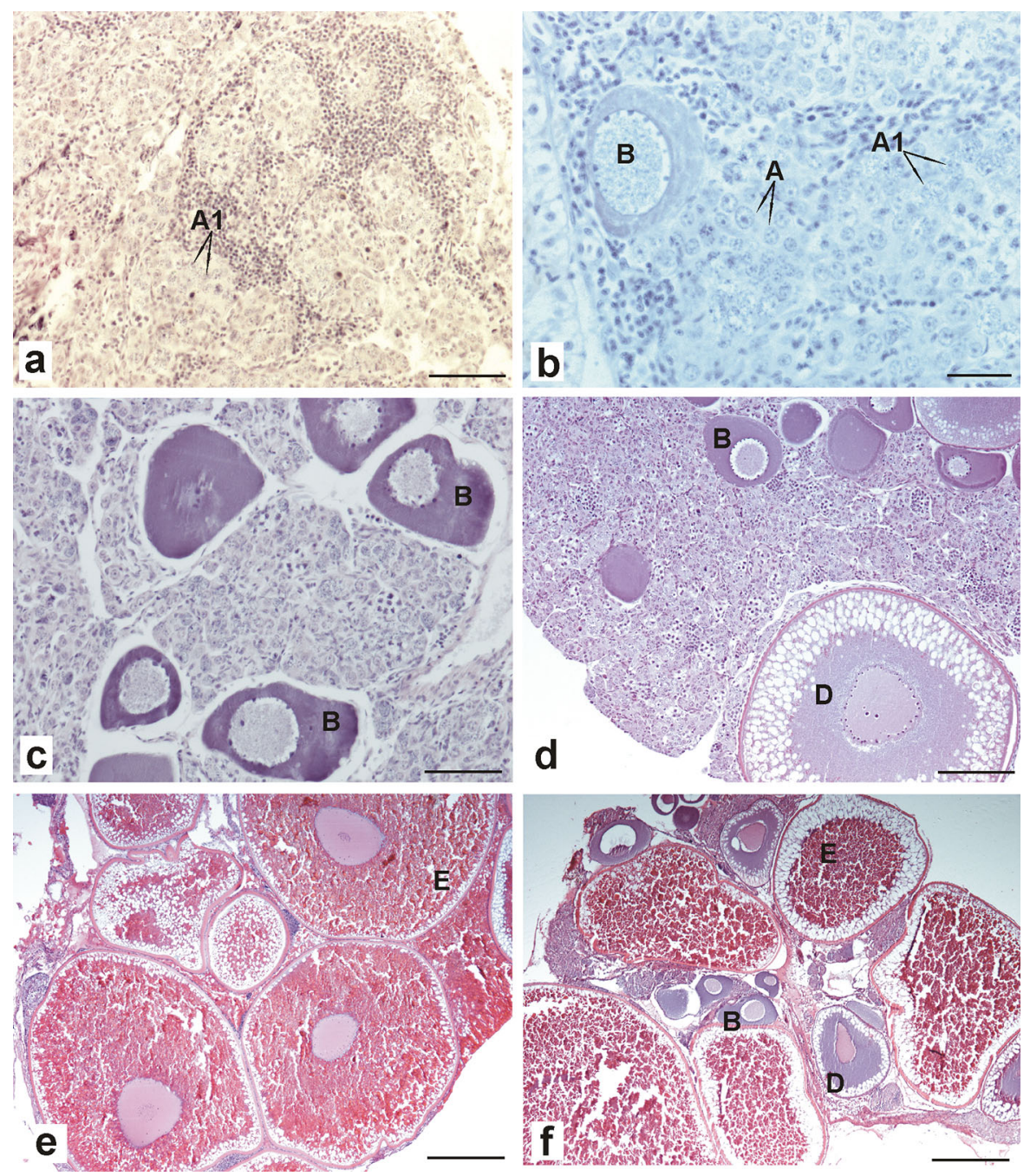

Fig. 3 Cross section of ovaries of diploid F1 hybrids derived from reciprocal crossing between $C$. taenia and C. elongatoides at different ages. a and $\mathbf{b} 7$ month: II maturity stage. $\mathbf{c} 15$ month:

circularis 'expressing' male maturity, do not indicate their reproductive capacity.

The duration of embryonic development of hybrids (this paper) was similar (c. two hours shorter) to $C$. taenia (Juchno et al., 2016). However, the percentage of hatching hybrid larvae was lower (15\% of TE and $32 \%$ of ET) in comparison with that in C. taenia (46\%) but the survival rate of all these larvae (Juchno et al., 2016) was similar.

The presented results using gonad histology confirmed excellent previous data by Choleva et al. (2012) which showed that among diploid hybrids of $C$. elongatoides and $C$. taenia only the females were

III maturity stage. d 18 month: IV maturity stage. e 2 years: V maturity stage. $\mathbf{f} 3$ years: $\mathrm{V}$ maturity stage. $A$ : oogonia, $A 1, B, D$, $E$ : stages of oocyte development. Bars $=150 \mu \mathrm{m}$

fertile and produced unreduced non-recombinant eggs, whereas males were infertile and paternal leakage of subgenomic amounts was not observed. Moreover, diploid hybrid females implemented the path of "stable diploid" and produced a rather small fraction of polyploid progeny (Choleva et al., 2012).

Diploid hybrid males (Choleva et al., 2012; present study), as well as triploid (Juchno et al., unpublished) and tetraploid Cobitis males (Juchno \& Boroń, 2006; Juchno et al., 2017), are infertile and disturbances in spermatogenesis begins in meiosis I. Most probably, the first signs of degeneration (shown here by pyknotic nucleus) appeared in spermatocytes I. 

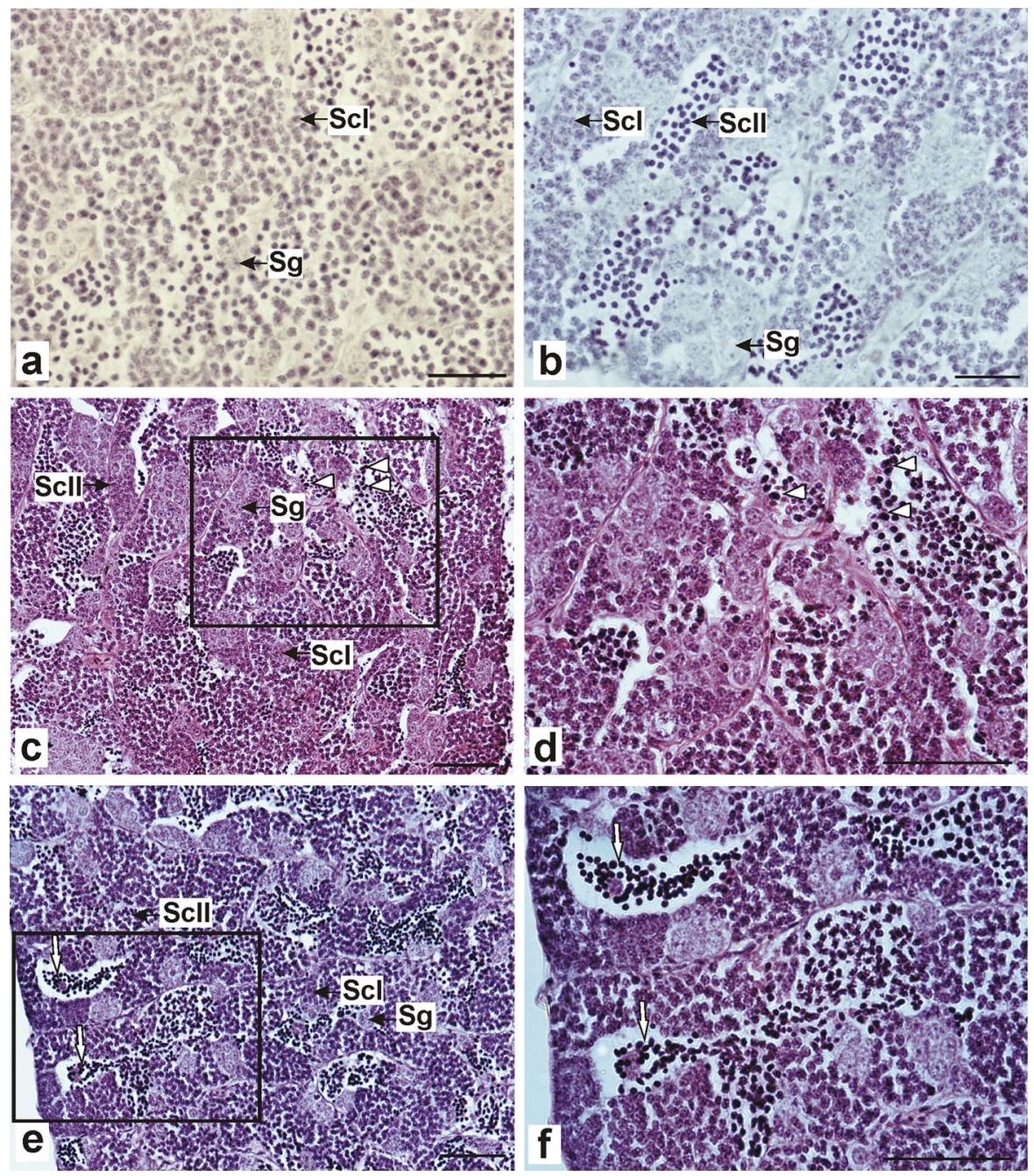

Fig. 4 Cross section of testes of diploid F1 hybrids derived from reciprocal crossing between $C$. taenia and C. elongatoides at different ages. a 7 month: II maturity stage. b 7 month: III maturity stage. c 15 month: III maturity stage. d (highmagnification view of the rectangular area show in c) 18 month:

According to Haldane's (1922) rule, F1 hybrid sterility depends on sex determination chromosomes, not on sex. The sterility of one sex of the F1 offspring of two animal species hybrids indicates a heterozygous sex. Thus, such sterility is not associated with a faster evolution of one of the sexes, but with the sex chromosomes, which probably cannot recombine during meiosis. Usually in fish, hybrid males are sterile, whereas females tend to be fertile (Yamamoto, 1969). Among the hybrids of the first or subsequent generations derived from crosses between species that differ in genome, there is a so-called "outbreeding

III maturity stage. e 2 years: III maturity stage; pyknotic cells (arrowheads). f (high-magnification view of the rectangular area show in e) 3 years: III maturity stage; pyknotic cells in the lumen of the tubules (arrow). Sg: spermatogonia, ScI: primary spermatocytes, Sc II: secondary spermatocytes. Bars $=150 \mu \mathrm{m}$

depression", i.e. a decrease in mean survival, health and fertility (Gharrett et al., 1999). The Cobitis hybrids in the present study had lower reproductive success than C. taenia as a parental species (Juchno et al., 2016).

Mature diploid Cobitis hybrids attained a similar length (about $45-50 \mathrm{~mm}$ ) as other Cobitis males with external features of sexual dimorphism (Bohlen et al., 2008). The ET hybrid females appeared to grow faster and attained longer lengths than males at the same age. Moreover, such hybrids were significantly longer than TE hybrids, probably due to the influence of the 

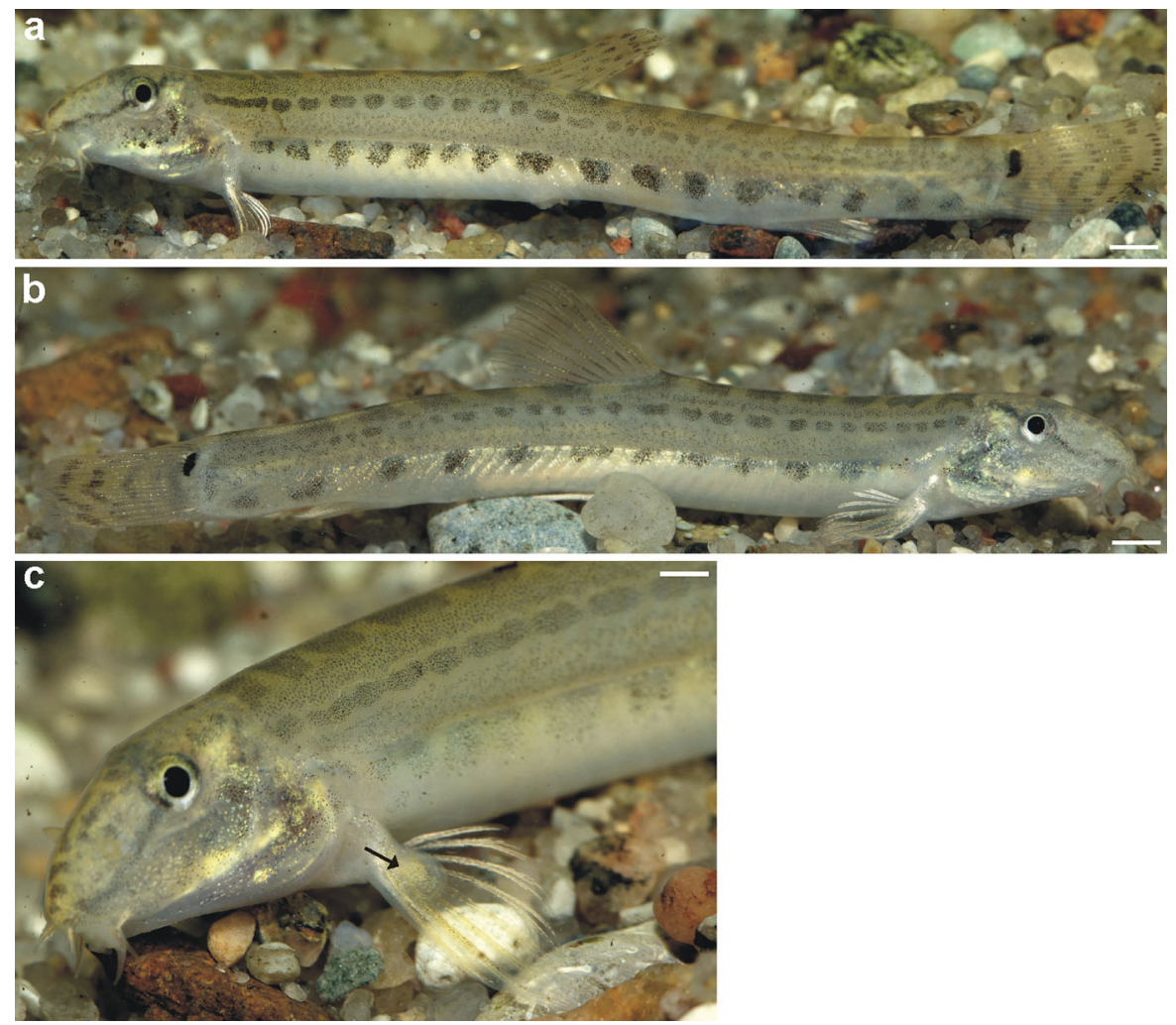

Fig. 5 Hybrid progeny derived from the back-crossing between TE females and C. taenia males. a Female, b Male, c Male, arrow point to the lamina circularis

genome of $C$. elongatoides females, which attain longer body length than $C$. taenia.

Diploid hybrid (TE and ET) females of Cobitis matured and their oocytes were fertilized with the sperm of $C$. taenia, resulting in properly developing offspring (Choleva et al., 2012; this study). The obtained data on the reproductive ability of diploid Cobitis hybrid females and the lack of this ability in males seem to reflect their presence in natural conditions. Diploid hybrid males occur less often than triploid and tetraploid ones or they are absent since diploid hybrid females exist and reproduce clonally or sexually (Choleva et al., 2012).

Previous research has suggested that the experimentally obtained progeny of $C$. taenia and $C$. elongatoides show sexual parity (Choleva et al., 2012). Somewhat different data were presented in this study, which found that among TE and ET offspring slightly more, respectively, females and males occurred. This result is difficult to interpret and requires confirmation. Moreover, sex parity documented among all analysed diploid hybrids would reflect the sex ratio in nature if they could create a bisexual population.

Previously, the infertility of diploid hybrid Cobitis males was indicated by a lack of fertilized eggs (Choleva et al., 2012), whereas in the current study, it was documented using gonad histology that diploid, morphologically mature Cobitis hybrid males do not produce spermatozoa, even after hormonal stimulation. The blocking mechanism for the formation of spermatozoa still remains unclear (Choleva et al., 2012). The histological analysis indicates that in the testes of $C$. taenia and $C$. elongatoides, reciprocal hybrid males meiosis at least commenced due to the presence of spermatocytes, but further this process does not occur properly.

Sterile hybrid males of Cobitis hankugensis Kim, Park, Son \& Nalbant 2003 and Iksookimia longicorpa (Kim, Choi \& Nalbant, 1976) possessed a few, but deformed, spermatozoa (Park et al., 2011). In turn, histological analysis of the gonads of reciprocal 
$2 n$ hybrids of Misgurnus mizolepis Günther, 1888 and M. anguillicaudatus (Cantor, 1842) indicated their sexual maturity; mature oocytes or sperm were observed (Park et al., 2006).

The back-crossing conducted in the present study indicated the reproductive capacity of F1 diploid hybrid TE females with $C$. taenia males but not with $C$. elongatoides males. The latter crossing attained the only stage of gastrula. In contrast, such backcrosses were successful in experiments described by Choleva et al. (2012). This can have many causes, for example, differences between the two methodological approaches. Natural spawning (without stimulation by hormones) conducted by Choleva et al. (2012) took place in an aquarium, whereas in the current study, fertilization was done in Petri dishes and the developing eggs were then transferred to a small aquarium.

Hybridization plays a significant role in the evolution and formation of new species (Choleva et al., 2012). Among naturally occurring fish, interspecific or intergeneric hybrids are mostly described in Cyprinidae (Fishelson et al., 1996; Hayden et al., 2010), Acipenseridae (Birstein et al., 2002) and Cobitidae (Janko et al., 2007; Choleva et al., 2012). Sometimes interspecific hybrids appear to be fertile, giving rise to new species. It is believed that hybrids may be better adapted to changing environmental conditions as a result of favorable gene combinations (Hayden et al. 2010). The mechanism and general principles of hybridization, asexuality, polyploidy and speciation are still problematic and well discussed. Polyploidization, chromosomal rearrangements and genomic incompatibilities have been identified as the causes of intrinsic postzygotic isolation of hybrids (Hoffmann \& Rieseberg, 2008; Wolf et al., 2010). According to the Dobzhansky-Müller model of hybrid incompatibility in closely related species, some particularly rapidly evolving genes are changing so much that their proteins could make the hybrid offspring sexually incompatible and sterile. Several hybrid incompatibility genes have been successfully identified (Wolf et al., 2010).

Clonal asexual females, such as diploid and polyploid hybrid Cobitis females, are considered as an intermediate stage to creating new species via hybridization and polyploidization (Vrijenhoek, 1998; Arai \& Fujimoto, 2013). For example, it has been proven that tetraploids of Iberian Squalius alburnoides (Steindachner, 1866) from populations in the Douro drainage resumed normal meiosis after undergoing intermediate processes of asexual reproduction to give rise to a new sexually reproducing polyploid species, which are better adapted to a new habitat (Cunha et al., 2008). Tetraploids of Cobitis in European populations are scarce, it was previously documented that triploid Cobitis females produce tetraploids in crosses with $C$. taenia males (Juchno et al., 2014). Even though such tetraploids are clearly less viable than simultaneously gynogenetically originated triploids, they can have an evolutionary future.

Recently, Janko et al. (2017), using Cobitis complex as model and widely discussed published data, formulated a new hypothesis of hybrid asexuality as an inherent stage of the speciation process that arises before other Dobzhansky-Müller incompatibilities take over the isolation of reproduction. According to this hypothesis, hybrid asexuality is a primary postzygotic barrier between nascent species (Janko et al., 2017). Hybridization and hybrid fitness depend on the genetic distance between hybridizing species (Seehausen et al., 2014) which has also been proven in Cobitis species (Janko et al., 2017). Recently diverged $C$. taenia and $C$. pontica were hybridized, producing mostly fertile and recombining progeny of both sexes. Hybrids of substantially diverged species, e.g. $C$. elongatoides and C. taenia, cannot mediate gene flow, so these species hybridize and produce sterile males and fertile females (Janko et al., 2017) which was indicated by Choleva et al. (2012) and confirmed based on the structure of gonads in the present study.

\section{Conclusions}

The presented results on the embryonic and larval development, as well as reproductive capabilities, of diploid F1 hybrids between C. taenia and C. elongatoides provide new data on the biology of Cobitis hybrids. The fertility of hybrid females and the sterility of hybrid males, confirmed for the first time by the structure of their gonads, indicate that males are the heterozygous sex. The results form the basis for a discussion on the role of diploid hybrids in the evolution of Cobitis as stepping stones in the formation of new species via hybridizations and polyploidy or as an element of new species isolation via asexuality and sterility. 
Acknowledgements This study was supported in part by the National Science Centre (NCN), Poland, Grant number N N303 068834, and in part by Grant number 2011/03/B/NZ8/02982 carried out at the University of Warmia and Mazury in Olsztyn, Poland. We would like to express special thanks to dr Karel JANKO and the other anonymous Reviewers for improvements of the manuscript.

Open Access This article is distributed under the terms of the Creative Commons Attribution 4.0 International License (http:// creativecommons.org/licenses/by/4.0/), which permits unrestricted use, distribution, and reproduction in any medium, provided you give appropriate credit to the original author(s) and the source, provide a link to the Creative Commons license, and indicate if changes were made.

\section{References}

Arai, K. \& T. Fujimoto, 2013. Genomic constitution and atypical reproduction in polyploid and unisexual lineages of the Misgurnus loach, a teleost fish. Cytogenetic and Genome Research 140: 226-240.

Birstein, V. J., P. Doukakis \& R. DeSalle, 2002. Molecular phylogeny of Acipenseridae: nonmonophyly of Scaphirhynchinae. Copeia 2: 287-302.

Bohlen, J., J. Freyhof \& A. Nolte, 2008. Sex ratio and body size in Cobitis elongatoides and Sabanejewia balcanica (Cypriniformes, Cobitidae) from a thermal spring. Folia Zoologica 57(1-2): 191-197.

Boron, A., 2003. Karyotypes and cytogenetic diversity of the genus Cobitis (Pisces, Cobitidae) in Poland: a review. Cytogenetic evidence for a hybrid origin of some Cobitis triploids. Folia Biologica 51(Suppl): 49-54.

Boroń, A. \& J. Kotusz, 1999. A preliminary report and karyotype of a new Cobitis species in the ichthyofauna of Poland. Cytobios 98: 59-64.

Boroń, A., C. Ozouf-Costaz, J.-P. Coutanceau \& K. Woroniecka, 2006. Gene mapping of 28S and 5S rDNA sites in the spined loach Cobitis taenia (Pisces, Cobitidae) from a diploid population and a diploid-tetraploid population. Genetica 128(7): 1-79.

Choleva, L. \& K. Janko, 2013. Rise and persistence of animal polyploidy: evolutionary constraints and potential. Cytogenetic and Genome Research 140: 151-170.

Choleva, L., K. Janko, K. De Gelas, J. Bohlen, V. Šlechtová, M. Rábová \& P. Ráb, 2012. Synthesis of clonality and polyploidy in vertebrate animals by hybridization between two sexual species. Evolution 66(7): 2191-2203.

Choleva, L., Z. Musilova, A. Kohoutova-Sediva, J. Paces, P. Rab \& K. Janko, 2014. Distinguishing between incomplete lineage sorting and genomic introgressions: Complete fixation of allospecific mitochondrial DNA in a sexually reproducing fish (Cobitis; Teleostei), despite clonal reproduction of hybrids. PLoS ONE 9: e80641.

Comai, L., 2005. The advantages and disadvantages of being polyploid. Nature Review Genetics 6: 836-846.

Cunha, C., I. Doadrio \& M. M. Coelho, 2008. Speciation towards tetraploidization after intermediate processes of non-sexual reproduction. Philosophical Transactions of the Royal Society B: Biological Sciences 363: 2921-2929.

Fishelson, L., G. Menachem, J. van Vuren \& R. Manelis, 1996. Some aspects of the reproductive biology of Barbus spp., Capoeta damascina and their hybrids (Cyprinidae, Teleostei) in Israel. Hydrobiologia 317: 79-88.

Gharrett, A. J., W. W. Smoker, R. R. Reisenbichler \& S. G. Taylor, 1999. Outbreeding depression in hybrids between odd- and even-broodyear pink salmon. Aquaculture 173: 117-129.

Haldane, J. B. S., 1922. Sex ratio and unisexual sterility in hybrid animals. Journal of Genetics 12: 101-109.

Hayden, B., D. Pulcini, M. Kelly-Quinn, M. O’Grady, J. Caffrey, A. McGrath \& S. Mariani, 2010. Hybridisation between two cyprinid fishes in a novel habitat: genetics, morphology and life-history traits. BMC Evolutionary Biology 10: 169-180.

Hoffmann, A. A. \& L. H. Rieseberg, 2008. Revisiting the impact of inversions in evolution: from population genetic markers to drivers of adaptive shifts and speciation? Annual Review of Ecology, Evolution, and Systematics 39: 21-42.

IUCN, 2017. The IUCN Red List of Threatened Species. Version 2017-3. http://www.iucnredlist.org.

Janko, K., J. Bohlen, D. Lamatsch, M. Flajshans, J. Epplen, P. Rab, P. Kotlik \& V. Slechtova, 2007. The gynogenetic reproduction of diploid and triploid hybrid spined loaches (Cobitis, Teleostei), and their ability to establish successful clonal lineages - on the evolution of polyploidy on asexual vertebrates. Genetica 131(2): 185-194.

Janko, K., J. Kotusz, K. De Gelas, V. Šlechtová, Z. Opoldusová, P. Drozd, L. Choleva, M. Popiołek \& M. Baláž, 2012. Dynamic formation of asexual diploid and polyploid lineages: multilocus analysis of Cobitis reveals the mechanisms maintaining the diversity of clones. PLoS ONE 7(9): e45384. https://doi.org/10.1371/journal.pone.0045384.

Janko, K., J. Pačes, H. Wilkinson-Herbots, R. J. Costa, J. Roslein, P. Drozd, N. Iakovenko, J. Rídl, M. Hroudová, J. Kočí, R. Reifová, V. Šlechtová \& L. Choleva, 2017. Hybrid asexuality as a primary postzygotic barrier between nascent species: on the interconnection between asexuality, hybridization and speciation. Molecular Ecology. https:// doi.org/10.1111/mec.14377.

Juchno, D. \& A. Boron, 2006. Comparative histology of the testes of the spined loach Cobitis taenia L. and natural allotetraploids of Cobitis (Pisces, Cobitidae). Hydrobiologia 573: 45-53.

Juchno, D., A. Boroń \& J. Gołaszewski, 2007. Comparative morphology and histology of the ovaries of the spined loach Cobitis taenia L. and natural allopolyploids of $\mathrm{Co}$ bitis (Cobitidae). Journal of Fish Biology 70: 1392-1411.

Juchno, D., O. Jabłońska, A. Boroń, R. Kujawa, A. Leska, A. Grabowska, A. Nynca, S. Świgońska, M. Król, A. Spóz, N. Laskowska \& M. Lao, 2014. Ploidy-dependent survival of progeny arising from crosses between natural allotriploid Cobitis females and diploid C. taenia males (Pisces, Cobitidae). Genetica 142: 351-359.

Juchno, D., A. Boroń, J. Szlachciak \& R. Kujawa, 2016. Early development and post embryonic skeletal morphology of the progeny of spined loach Cobitis taenia L. (Teleostei, Cobitidae) and its naturally occurred allotriploids. Folia Biologica (Kraków) 64(3): 153-162. 
Juchno, D., A. Pecio, A. Boroń, A. Leska, O. Jabłońska, B. I. Cejko, R. K. Kowalski, S. Judycka \& M. Przybylski, 2017. Evidence of the sterility of allotetraploid Cobitis loaches (Teleostei, Cobitidae) using testes ultrastructure. Journal of Experimental Zoology 327A: 66-74.

Kimmel, C. B., W. W. Ballard, S. R. Kimmel, B. Ullmann \& T. F. Schilling, 1995. Stages of embryonic development of the zebrafish. Developmental Dynamics 203: 253-310.

Kotusz, J., 2008. Morphological relationships between polyploid hybrid spined loaches of the genus Cobitis (Teleostei: Cobitidae) and their parental species. Annales Zoologici 58(4): 891-905.

Marconato, A. \& M. B. Rasotto, 1989. The biology of a population of spined loach Cobitis taenia. L. Bolletino del Museo di Zoologia 56: 73-80.

Park, I.-S., Y. K. Nam \& D. S. Kim, 2006. Growth performance, morphometric traits and gonad development of induced reciprocal diploid and triploid hybrids between the mud loach (Misgurnus Mizolepis Günther) and cyprinid loach (Misgurnus anguillicaudatus Cantor). Aquaculture Research 37: 1246-1253.

Park, J. Y., I. S. Kim \& M. H. Ko, 2011. Characteristics of rare males in the cobitid unisexual complex, Cobitis hankugensis-Iksookimia longicorpa. Folia Zoologica 60(4): 290-294.

Rasotto, M. B., 1992. Gonadal Differentiation and the mode of sexuality in Cobitis taenia (Teleostei; Cobitidae). Copeia 1: 223-228.

Saitoh, K., W. J. Chen \& R. L. Mayden, 2010. Extensive hybridization and tetrapolyploidy in spined loach fish. Molecular Phylogenetics and Evolution 56: 1001-1010.
Seehausen, O., R. K. Butlin, I. Keller, C. E. Wagner, J. W. Boughman, P. A. Hohenlohe, C. L. Peichel, G.-P. Saetre, C. Bank, A. Brännström, A. Brelsford, C. S. Clarkson, F. Eroukhmanoff, J. L. Feder, M. C. Fischer, A. D. Foote, P. Franchini, C. D. Jiggins, F. C. Jones, A. K. Lindholm, K. Lucek, M. E. Maan, D. A. Marques, S. H. Martin, B. Matthews, J. I. Meier, M. Möst, M. W. Nachman, E. Nonaka, D. J. Rennison, J. Schwarzer, E. T. Watson, A. M. Westram \& A. Widmer, 2014. Genomics and the origin of species. Natural Review of Genetic 15: 176-192.

Stolzenberg, N., T. B. Nguyen, M. D. Salducci \& L. Cavalli, 2009. Influence of environment and mitochondrial heritage on the ecological characteristics of fish in a hybrid zone. PLoS ONE 4(6): e5962. https://doi.org/10.1371/journal. pone.0005962.

Wolf, J. B., W. J. Lindell \& N. Backström, 2010. Speciation genetics: current status and evolving approaches. Philosophical Transactions of the Royal Society B: Biological Sciences 365: 1717-1733.

Vasil'ev, P., K. D. Vasil'eva \& A. G. Osinov, 1989. Evolution of diploid-triploid-tetraploid complex in fishes of the genus Cobitis (Pisces, Cobitidae). In Dawley, R. M. \& J. P. Bogart (eds), Evolution and Ecology of Unisexual Vertebrates. New York State Museum, Albany: 153-169.

Vrijenhoek, R. C., 1998. Clonal organisms and the benefits of sex. In Carvalho, G. R. (ed.), Advances in molecular ecology. IOS Press, Amsterdam: 151-172.

Yamamoto, T., 1969. Sex differentiation. In Hoar, W. S. \& D. J. Randall (eds), Fish physiology. Academic Press, New York: 117-175. 